Tema: Aciaria Oxigênio

\title{
MELHORIA DO REFRATÁRIO DOS CONVERTEDORES DA ACIARIA USIMINAS CUBATÃO*
}

\author{
Haysler Apolinário Amoroso Lima ${ }^{1}$ \\ Lara Crysthine Paes Ret ${ }^{2}$ \\ Ivan Rodrigues ${ }^{3}$
}

\begin{abstract}
Resumo
O desempenho de uma Aciaria depende da estabilidade dos equipamentos industriais. A conservação do refratário do convertedor garante produtividade, evitando paradas para reparo e campanhas antecipadas. A proteção do revestimento como um todo garante uma maior eficiência do sopro combinado, obtendo ganhos de qualidade e redução de ressopro. O presente trabalho refere-se à busca de soluções de engenharia para aumentar o desempenho do refratário dos convertedores e conservação do sopro combinado pelas ventaneiras. Através do estudo dos mecanismos de desgaste dos refratários, optou-se pelo ajuste dos escorificantes, melhoria das práticas de reparo com escória, mudança do projeto dos tijolos e ajuste da vazão das ventaneiras. Com as melhorias implantadas, houve redução do consumo de massa de projeção e aumento em $100 \%$ da vida útil das ventaneiras.
\end{abstract}

Palavras-chave: Convertedores; Refratários; Ventaneiras; Ajuste da escória.

\section{IMPROVEMENT OF REFRACTORY CONVERTERS OF THE USIMINAS CUBATÃO STEEL PLANT}

\section{Abstract}

The performance of a steel plant is directly linked to the reliability of the industrial equipment. In case of the converter, the conservation of the refractory ensures a high productivity by avoiding downtime for repair and non-planed campaigns. The conservation of the refractory also contributes to the efficiency of the combined blowing process, a quality improvement and noise reduction due to a reduction of reblows. This paper is focused on the search for engineering solutions to increase the performance of the converter refractory and the conservation of the combined blowing by tuyeres. By analyzing the different influences to the refractory wear, an optimization of the slag builders, an improvement of the repair practices using slag, a modification of the brick layout and an adjustment of the flow of tuyeres could be achieved. Finally, all implemented improvements, led to a significant reduction of the repair mass consumption and a $100 \%$ increase of the lifetime of the tuyeres.

Keywords: Converter; Refractory; Tuyeres; Slag adjust.

Engenheiro metalurgista, Gerência Técnica da Aciaria, Usiminas Cubatão, SP, Brasil.

Engenheira metalurgista, Gerência Técnica da Aciaria, Usiminas Cubatão, SP, Brasil.

Técnico metalurgista, Gerência de Convertedores da Aciaria, Usiminas Cubatão, SP, Brasil.

* Contribuição técnica ao 450 Seminário de Aciaria - Internacional, 25 a 28 de maio de 2014, Porto Alegre, RS, Brasil. 


\section{INTRODUÇÃO}

O processo de fabricação do aço em convertedores inicia com o carregamento de gusa liquido, sucata de aço, cal e fundentes. Por meio do sopro de oxigênio, elementos como o carbono, silício, manganês e o próprio ferro, transformam-se em óxidos que vão para a escória ou se incorporam ao gás $\left(\mathrm{CO}\right.$ e $\left.\mathrm{CO}_{2}\right)$. Este processo também chamado de refino primário é o pulmão das aciarias modernas. $O$ aço em seguida é vazado para a panela, que tem a função de auxiliar no tratamento secundário (Forno Panela, Desgaseificiador RH, Estação de Borbulhamento etc). Nesta etapa, o aço é submetido a processos de desgaseificação, dessulfuração, descarburação, desoxidação e aquecimento.

Durante o processo de fabricação do aço é necessário o conhecimento prévio das reações de refino, do mecanismo de formação de escória e das características dos principais escorificantes utilizados. As reações químicas no convertedor objetivam a oxidação parcial do carbono, manganês, silício e a redução de impurezas tal como o fósforo. A formação de uma boa escória é de vital importância para a conservação do refratário, neste caso deve-se ajustá-la para o aumento da basicidade, neutralizando principalmente a sílica e objetivando a saturação em $\mathrm{MgO}$, com o foco na conservação do revestimento de trabalho.

O projeto refratário deve ser adequado as condições operacionais, bem como equilibrar com os diferentes mecanismos de desgaste das diversas regiões presentes no convertedor. Para isso o projeto deve contemplar os seguintes critérios: Seleção do produto para cada região, geometria do revestimento, processo de dilatação térmica dos tijolos, facilidade de montagem e tipos de construção refratária [1].

Através de todo o estudo referente ao mecanismo de desgaste, é possível desenhar o material mais adequado para cada região, com isso o balanceamento garante uma maior segurança operacional e um menor custo específico do refratário.

Já o sopro combinado teve como grande diferencial trazer as reações entre escória e metal próximo do equilíbrio termodinâmico, garantindo também uma melhor homogeneização térmica e química do banho. A injeção do argônio pelo fundo promove uma agitação adicional favorecendo a desfosforação, aumentando o teor de manganês no banho e reduzindo o teor de ferro na escória. Com a melhoria das condições do refino, tem-se um aumento do rendimento metálico, redução do consumo de fundentes e aumento da vida do refratário [1].

A vida útil de uma ventaneira geralmente não acompanha a vida de um convertedor, necessitando o seu fechamento antecipado para evitar acidentes operacionais.

Os mecanismos ligados ao desgaste das ventaneiras estão associados às condições de trabalho, entre eles o choque térmico devido à passagem do gás inerte pelas ventaneiras. De acordo com um estudo do sobre mecanismos de desgaste [2], o "back attack" é o fenômeno relacionado ao impacto do gás na ventaneira ao retornar após expansão/rompimento, este processo cíclico desencadeia o desgaste do refratário. Outros fatores estão ligados ao forno, entre eles temperatura do aço, qualidade da escória e abrasão pelo metal liquido.

Lima [3] estudou a configuração das ventaneiras e a análise do desgaste em relação a vazão de injeção, conseguiu obter resultados satisfatórios, dobrando a vida útil das ventaneiras. Através do uso de materiais consumíveis (ácido bórico) representando as ventaneiras foi possível estabelecer as condições necessárias para evitar o desgaste prematuro das ventaneiras. O modelo utilizado em acrílico representava um convertedor de $220 \mathrm{t}$. Este trabalho também correlacionou a técnica de reparo

\footnotetext{
* Contribuição técnica ao 450 Seminário de Aciaria - Internacional, 25 a 28 de maio de 2014, Porto Alegre, RS, Brasil.
} 
com escória e o uso de escorificantes, tal como a Dolomita Crua. Concluindo que a mudança de posicionamento das ventaneiras garantiu uma melhor proteção.

\subsection{Mecanismos de Desgaste}

Para qualquer projeto refratário há a necessidade de compreendermos as regiões do equipamento e quais mecanismos de desgaste envolvidos. O estudo dos convertedores LD é dividido em regiões, já que cada ponto é submetido a várias condições distintas. Com isso orienta-se a adequação do produto em termos de composição ou mesmo espessura de revestimento. A tabela 1 ilustra os mecanismos de desgaste por região:

Tabela 1. Zonas Criticas do Convertedor [1]

\begin{tabular}{|l|l|l|}
\hline Região & Sub-região & Fatores de Desgaste \\
\hline Boca & Boca & Remoção mecânica (limpeza), erosão e abrasão \\
\hline \multirow{4}{*}{ Cone } & Cone & $\begin{array}{l}\text { Oxidação (pós combustão), abrasão (arraste de gases e } \\
\text { particulados e choque térmico. }\end{array}$ \\
\cline { 2 - 3 } & $\begin{array}{l}\text { Furo de } \\
\text { Vazamento }\end{array}$ & Oxidação, ataque por escória e erosão (vazamento do aço). \\
\hline \multirow{4}{*}{ Cilindro } & Linha de Escória & Corrosão e Oxidação. \\
\cline { 2 - 3 } & Vazamento & Oxidação, erosão (movimento de metal/escória). \\
\cline { 2 - 3 } & Zona de Impacto & Choque mecânico e erosão (carregamento do gusa líquido). \\
\cline { 2 - 3 } & Munhões & Oxidação, corrosão e choque térmico. \\
\hline \multirow{2}{*}{ Sola } & Sola & Choque térmico e erosão. \\
\cline { 2 - 3 } & Ventaneira & Erosão, oxidação, rebote (back attack) e choque térmico. \\
\hline
\end{tabular}

A corrosão dos refratários é o principal motivo de degradação do revestimento de trabalho. O processo inicia com a oxidação do carbono do refratário ( $\mathrm{MgO}-\mathrm{C})$ que tem a função de reduzir a molhabilidade do metal/escória, com isso ocorre a infiltração de escória e aço na matriz refratária. Dependendo de seus constituintes os mesmos formam fases de baixo ponto de fusão e com isso ocorre a fusão da mesma. A agitação do metal/escória (erosão) provoca o desprendimento dos grãos grossos que ficam soltos na matriz. A Figura 1, mostra a corrosão de uma matriz de $\mathrm{MgO}-\mathrm{C}$.

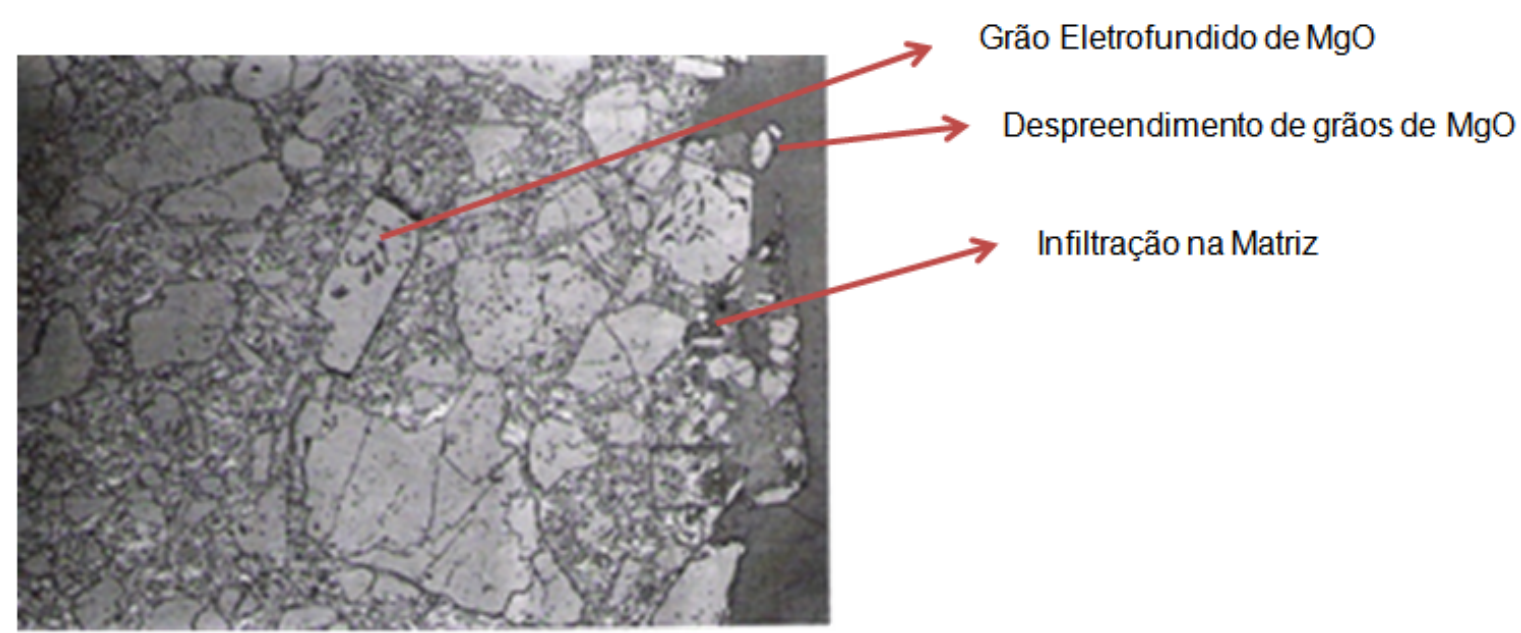

Figura 1. Corrosão do tijolo MgO-C [1].

* Contribuição técnica ao 450 Seminário de Aciaria - Internacional, 25 a 28 de maio de 2014, Porto Alegre, RS, Brasil. 
Outro fator que desencadeia o desgaste é a Abrasão que é o fenômeno de atrito com o refratário por partículas sólidas e gases. Já a erosão é o mecanismo que surge pelo movimento constante dos fluidos presentes na superfície do refratário.

Do ponto de vista térmico, a termoclase é o fenômeno que gera a fragmentação da superfície do refratário por intermédio de trincas geradas pelo gradiente térmico. A trinca é formada pela característica estrutural do refratário, onde o módulo de tração é menor que o de compressão, e quando ocorre um gradiente térmico surge uma oscilação cíclica que induz uma quantidade maior de defeitos propagando a trinca até sua fratura.

Neste trabalho objetivou-se o estudo aprofundado dos mecanismos de desgaste do convertedor, durante sua operação. Avaliando a taxa de desgaste por região e conhecendo as condições operacionais para formação de escória, fez-se um plano de ação baseando em uma pesquisa bibliográfica sobre as melhores práticas.

\section{METODOLOGIA}

Neste trabalho, fez-se uma análise dos principais problemas relacionados ao desgaste do refratário do convertedor da Aciaria de Cubatão. Através das medições efetuadas com o sistema de medição a laser, foi possível identificar os pontos críticos e com isso pesquisar os procedimentos recomendados para minimizar tal efeito. O trabalho baseou-se na pesquisa bibliográfica, comparando os resultados de outras usinas e em parceria com o atual fornecedor de refratário, na busca de materiais mais adequados para o nosso sistema operacional.

Em relação ao sopro combinado, a metodologia adotada baseou-se no trabalho realizado por Lima [3]. Buscando ajustar a vazão ideal das ventaneiras, minimizando o "back attack". O modelo desenvolvido neste trabalho baseou-se no estudo da modelagem física em um convertedor em acrílico em escala 1:8. Através de critérios de similaridade, foi possível padronizar a vazão das ventaneiras, evitando o desgaste e garantindo a homogeneização do banho imprescindível para o processo.

\subsection{Sopro Combinado - Número adimensional de vazão mássica}

Usando um modelo em acrílico, Lima [3] obteve os mesmos resultados de Lee et al. [2] referente ao modelo de desgaste das ventaneiras. $O$ número adotado foi chamado de Adimensional de Velocidade Mássica $\left(\mathrm{N}_{\mathrm{G}}\right)$. Dependendo do valor tinhase um maior ou menor desgaste nos bicos de injeção. A Figura 2 mostra a relação entre o $\mathrm{N}_{\mathrm{G}}$ e o desgaste das ventaneiras.

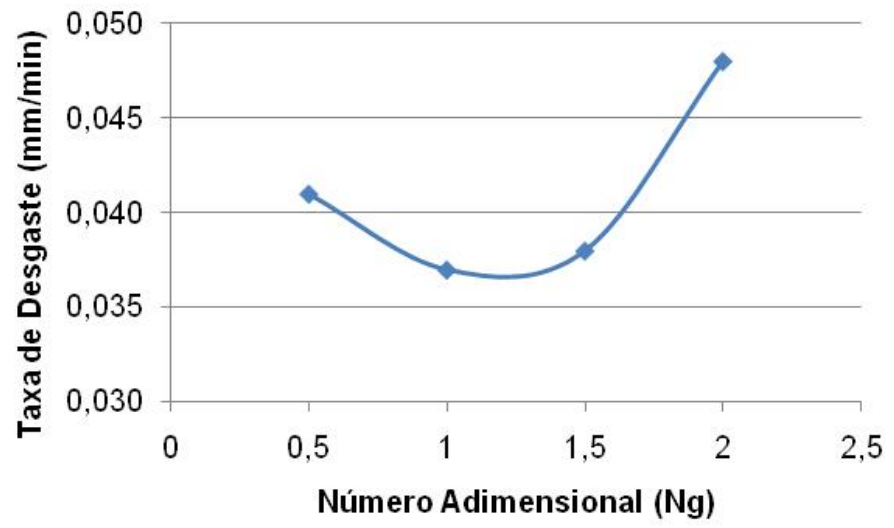

Figura 2. Taxa de desgaste versus $\mathrm{N}_{\mathrm{G}}[3]$.

* Contribuição técnica ao 450 Seminário de Aciaria - Internacional, 25 a 28 de maio de 2014, Porto Alegre, RS, Brasil. 


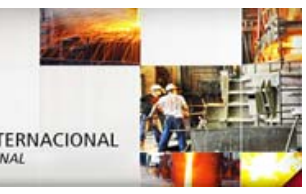

Onde o $\mathrm{N}_{\mathrm{G}}$ é representado pela equação abaixo:

$N_{G}=\frac{\rho . v}{\rho^{*} \cdot v^{*}}$, onde ( $\rho$ :densidade do gás na Temperatura e Pressão de trabalho, v: velocidade do gás; $\rho^{*}$ : densidade do argônio na CNTP, $v^{*}$ : velocidade do som)

- $\mathrm{N}_{\mathrm{G}}<1,0$ - regime de borbulhamento (Alto desgaste)

- $\mathrm{N}_{\mathrm{G}}=1 \sim 1,5-$ transição (Baixo desgaste)

- $\mathrm{N}_{\mathrm{G}}>1,5-$ jato desenvolvido (Alto Desgaste)

O mecanismo explicado para o desgaste na região $N_{G}<1,0$ é chamado de borbulhamento. Onde as bolhas estouram próximo ao tijolo, promovendo sua erosão. Já o mecanismo explicado para o desgaste na região $N_{G}>1,5$ é chamado de back attack. O qual as bolhas se rompem, ocorrendo um rebote responsável pela degração do tijolo refratário. A Figura 3 mostra o fenômeno do back attack.

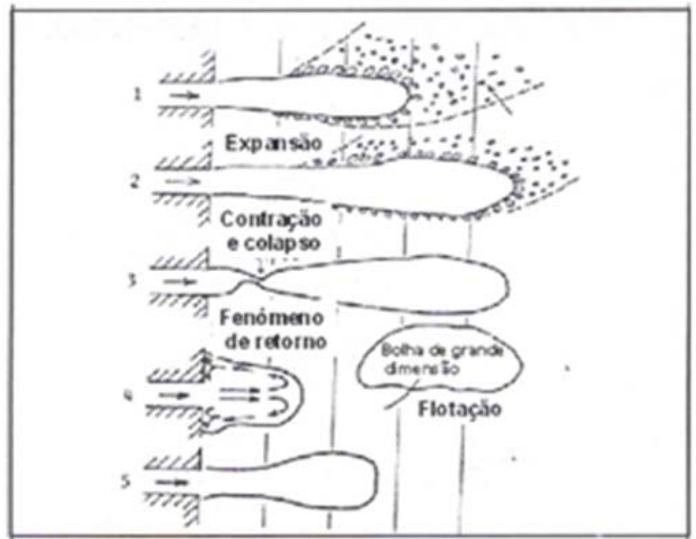

Figura 3. Fenômeno do back attack [1].

Uma forma de ajustar o número adimensional $\left(\mathrm{N}_{\mathrm{G}}\right)$ é alterando a vazão ou o diâmetro interno das ventaneiras. Com o aumento do diâmetro interno temos a queda da velocidade de passagem do gás.

No caso da Aciaria da Usiminas, optou-se pelo ajuste da vazão das ventaneiras. Pelo valor atual, foi necessário aumentar a vazão para $20 \%$, para sair da faixa $N_{G}<1$ (Borbulhamento).

\subsubsection{Reparo das ventaneiras com dolomita crua}

A dolomita crua é um carbonato formado pela combinação de $\mathrm{Mg}$ e $\mathrm{Ca}$, sendo sua fórmula dada por, $\mathrm{MgCO}_{3} \cdot \mathrm{CaCO}_{3}$. Ao atingir a temperatura critica de calcinação, 0 carbonato se dissocia liberando o $\mathrm{CO}_{2}$. Esta reação é endotérmica, o que provoca o resfriamento da escória.

Sendo assim, formulou-se a hipótese que ao adicionar na escória a dolomita crua, próximo a região desgastada das ventaneiras, ocorreria uma recuperação do local, sem a obstrução das ventaneiras. Devido à formação de $\mathrm{CO}_{2}$, os gases liberados, formariam canais, que permitiriam a passagem do argônio das ventaneiras. Logo haveria a formação de uma peça porosa em torno das ventaneiras. A Figura 4 mostra o fenômeno descrito acima.

* Contribuição técnica ao 45 Seminário de Aciaria - Internacional, 25 a 28 de maio de 2014, Porto Alegre, RS, Brasil. 


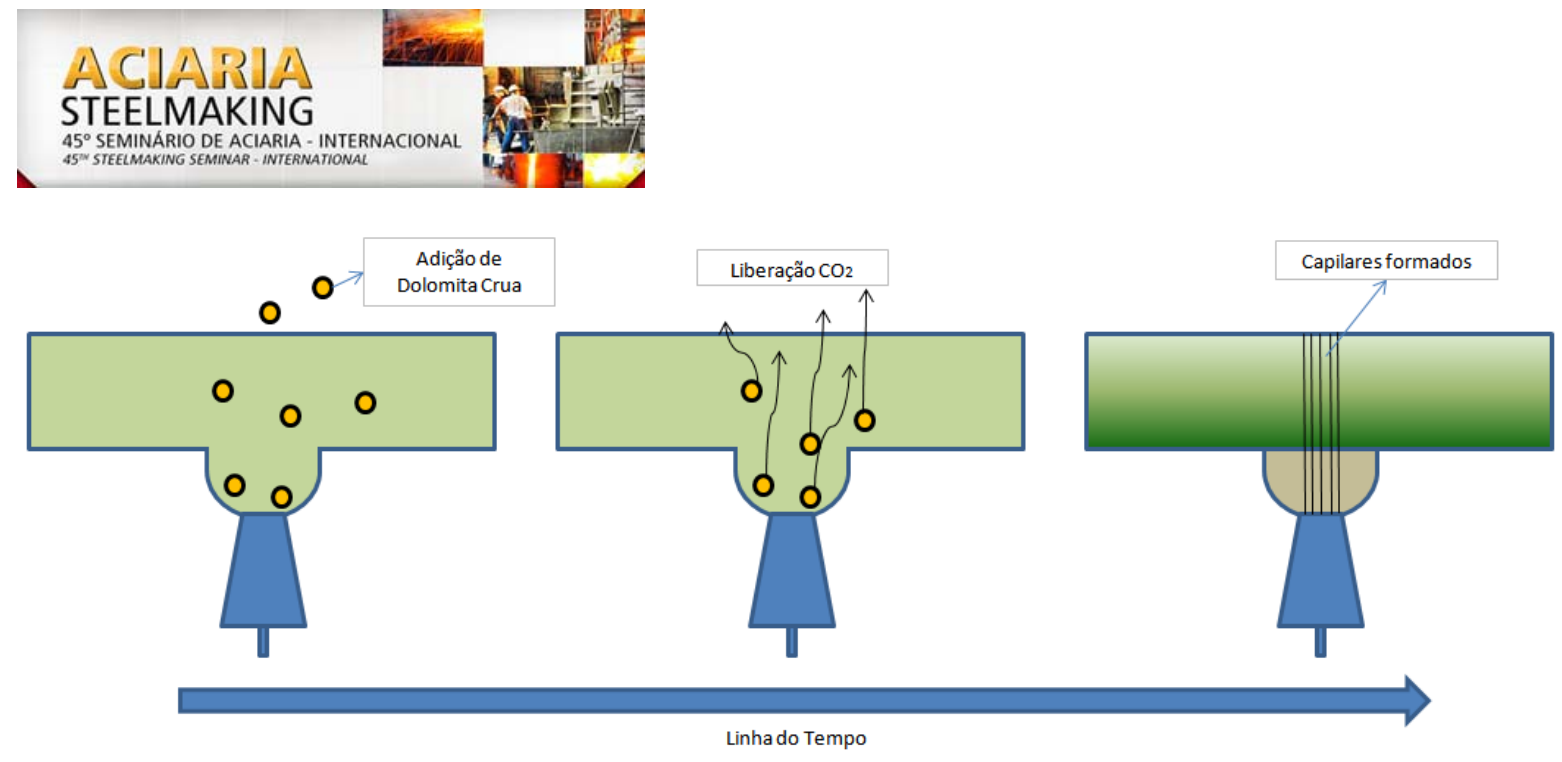

Figura 4. Hipótese sobre a formação de uma camada porosa nas ventaneiras.

Através deste modelo, implantou-se o reparo das ventaneiras com a dolomita crua após final do vazamento da escória.

Outra ação desenvolvida foi à modificação do padrão de acompanhamento das ventaneiras. Abaixo de $350 \mathrm{~mm}$ de residual, fecha-se a ventaneira após reparo com dolomita crua. Ao recuperar (Espessura $>500 \mathrm{~mm}$ ), abre-se novamente a ventaneira. O objetivo é garantir uma maior vida da ventaneira durante a campanha do convertedor, sem o risco de um acidente.

\subsubsection{Controle individual das ventaneiras}

Uma segunda hipótese formada neste trabalho foi sobre o controle individual das ventaneiras. Na Usiminas Cubatão têm-se dois tipos de projetos de ventaneiras. Um convertedor tem 10 ventaneiras com controle de vazão individual. $\mathrm{E}$ dois convertedores com 18 ventaneiras, sendo que uma válvula de vazão para cada 2 ventaneiras.

A hipótese formulada refere-se sobre, o caminho preferencial do argônio. O mesmo tende a passar pelo caminho mais fácil, sendo assim, se regularmos a vazão para $100 \mathrm{Nm}^{3} / \mathrm{h}$, a mesma é dividida em $50 \mathrm{Nm}^{3} / \mathrm{h}$ para cada ventaneira caso não houvesse diferença entre caminhos. Entretanto, o que pode ocorrer é que numa ventaneira passe $90 \mathrm{Nm}^{3} / \mathrm{h}$ e a outra $10 \mathrm{Nm}^{3} / \mathrm{h}$. O que ocasiona o desgaste antecipado da ventaneira de maior vazão, causando o fechamento da linha de argônio das duas ventaneiras. Foi feito um teste com a montagem de $50 \%$ das ventaneiras no convertedor 5 , para que o mesmo tenha o controle individual.

Com o controle individual, foi possível implantar a vazão ideal, modelada pelo número adimensional $\left(\mathrm{N}_{\mathrm{G}}\right)$.

\subsubsection{Ponto ótimo de consumo específico do convertedor}

Do ponto de vista do revestimento refratário, quanto maior o número de corridas, menor seu custo específico. Entretanto o consumo de massa não é linear e sim exponencial. A partir de certo número de corrida a frequência de reparo com massa é aumentada; reduzindo a disponibilidade do convertedor e aumento do custo final do refratário. Para determinar o ponto ótimo de término do convertedor, tem-se um gráfico correlacionando os mínimos e máximos de consumo, cuja curva é uma parábola. A alimentação dos dados é diária, dependendo do perfil de desgaste a curva se ajusta ao melhor ponto de término da campanha. Abaixo um exemplo de curva otimizada do revestimento (Figura 5).

\footnotetext{
* Contribuição técnica ao 45 Seminário de Aciaria - Internacional, 25 a 28 de maio de 2014, Porto Alegre, RS, Brasil.
} 

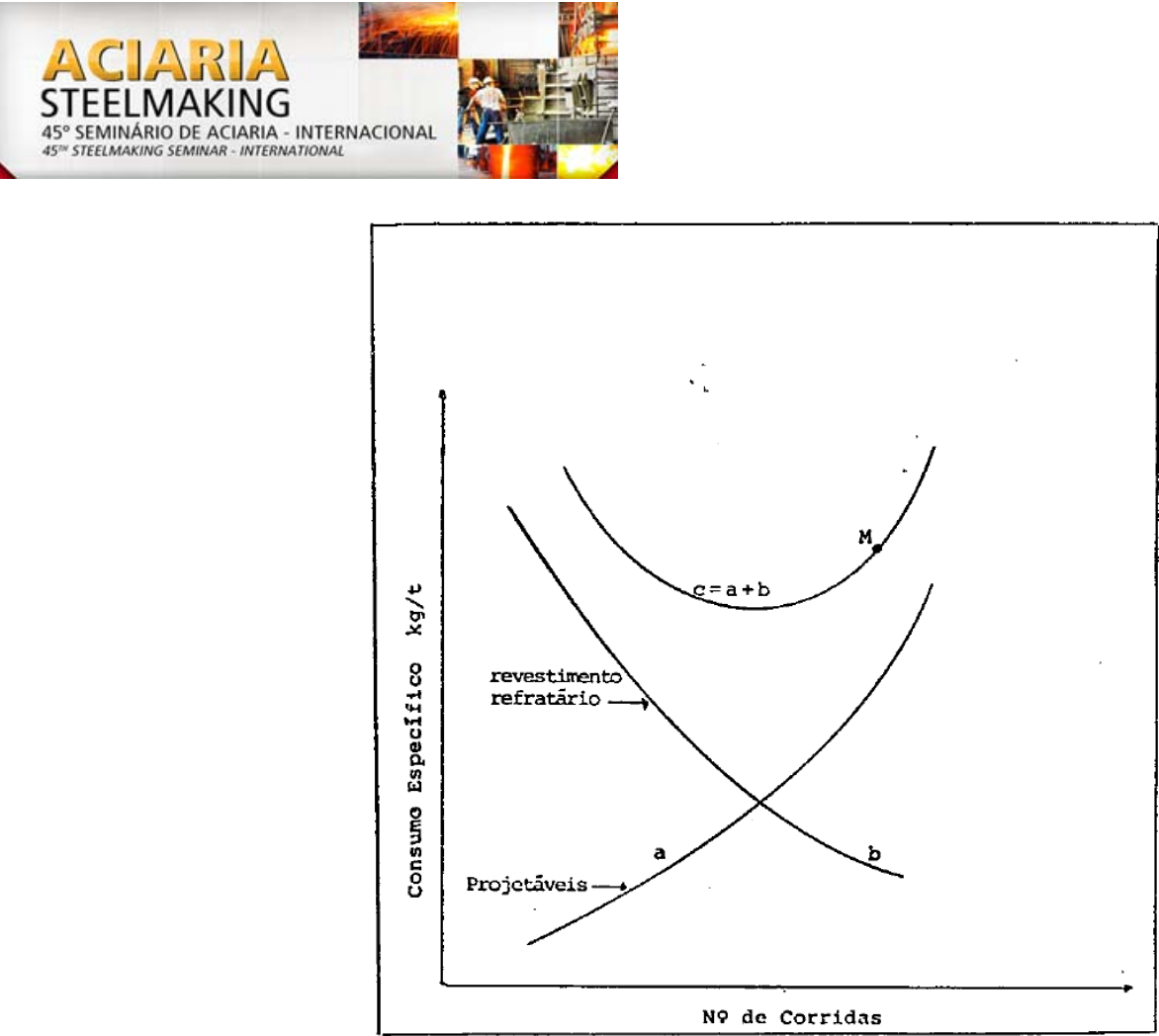

Figura 5. Curva de otimização da vida do Convertedor [4].

\subsection{Técnicas de Preservação do Refratário}

Dentro dos métodos atuais para preservação do refratário do convertedor, a técnica de saturação da escória com $\mathrm{MgO}$, é a de maior impacto no controle do processo [5]. O cálculo do $\mathrm{MgO}$ de saturação é baseado em equações empíricas, o qual correlaciona teor de Fe total, temperatura e relação $\mathrm{CaO} /\left(\mathrm{SiO}_{2}+\mathrm{P}_{2} \mathrm{O}_{5}\right)$.

Existem dois tipos de reparo com a escória utilizados na rotina operacional, sendo o mais comum o slag coating [1], o qual no final do vazamento do aço, vaza-se parte da escória, e dependendo da condição da escória, corrige-se com fontes de MgO (Dolomita crua ou calcinada). Faz-se o reparo (balança-se 4 vezes) para proteção da região do impacto, sola e região de vazamento. Esta técnica é mais simples, porém só protege as regiões descritas, o que não permite a proteção dos munhões.

A segunda técnica (mais efetiva) é o slag splashing [1], sendo que após a correção da escória (ajuste viscosidade e composição) faz-se o sopro com nitrogênio no fundo, projetando a escória nas paredes do convertedor.

O procedimento adotado neste trabalho foi somente o reparo com escória (slag coating), o qual se optou em vazar $2 / 3$ da escória e corrigir $1 / 3$ da escória restante com dolomita crua e calcinada.

A introdução da dolomita crua foi determinante nos resultados, a mesma tem um custo muito menor, e tem uma característica peculiar que é a alta capacidade de refrigeração (processo de calcinação), o qual permite que a escória esfrie e adere na parede do refratário.

Dentro do padrão de reparo adotado, implantaram-se restrições quanto esta técnica, dos quais podemos citar:

1. Temperaturas superiores a $1.700^{\circ} \mathrm{C}$;

2. Corridas com carbono menor que 250 ppm;

3. Corridas ressopradas;

4. Corridas com mais de 3 interrupções de sopro.

Outro processo em paralelo é o sistema de medição a laser o qual, por emissão de raios infravermelhos, projeta-se o perfil de desgaste do convertedor. Sendo assim é

* Contribuição técnica ao 45 Seminário de Aciaria - Internacional, 25 a 28 de maio de 2014, Porto Alegre, RS, Brasil. 
possível determinar os pontos críticos e atuar através de projeções de concreto e com isso recobrir a parte desgastada.

\subsection{Desenvolvimento de Novo Material para os Munhões}

O próximo passo foi o desenvolvimento de um material para a região dos munhões. Devida a alta oxidação gerada pelo sopro de oxigênio, os munhões são submetidos à perda do carbono contido. O material atual tem entre $17 \%$ a $20 \%$ de carbono, o que ajuda na resistência ao choque térmico, entretanto o material fica mais susceptível a oxidação e perda do carbono. Com isso ocorre mais infiltração de metal/escória, o que permite o desprendimento do material, mecanismo este que é responsável pelo desgaste do tijolo.

Neste trabalho, optou-se em desenvolver um tijolo com menor teor de carbono, tomando o cuidado em não perder as outras propriedades citadas anteriormente. Sendo a Tabela 2, mostra a situação anterior e a atual com o novo material.

Tabela 2. Materiais utilizados para os munhões do convertedor [6]

\begin{tabular}{|l|c|c|}
\hline \multicolumn{1}{|c|}{ Dados } & $\begin{array}{c}\text { Material } \\
\text { Antigo }\end{array}$ & $\begin{array}{c}\text { Material } \\
\text { Desenvolvido }\end{array}$ \\
\hline $\mathrm{MgO}(\%)$ & 90 a 94 & 90,0 \\
\hline $\mathrm{C}(\%)$ & 17 a 20 & 14,0 \\
\hline Densidade aparente $\left(\mathrm{g} / \mathrm{cm}^{3}\right)$ & 2,81 a 2,91 & 2,97 \\
\hline Porosidade $(\%)$ & 1,5 a 5,0 & 3,0 \\
\hline Resistência a Compressão a Quente $(\mathrm{MPa})$ & 13,0 & 18,0 \\
\hline
\end{tabular}

\subsection{Qualidade dos Escorificantes}

A formação da escória é uma das etapas mais importantes no refino primário, a sua rápida formação permite a absorção dos elementos indesejáveis, aumento do rendimento metálico e permite a proteção do refratário após o refino (slag coating).

\subsubsection{Minério de manganês}

A adição do minério de manganês objetiva o aumento do rendimento do manganês no aço. Entretanto, sua formulação, aumenta a fluidificação da escória (reduz o ponto de fusão). Uma escória mais líquida permite uma maior penetração pelos poros do refratário, e consequentemente um maior desgaste.

Neste trabalho optou-se em eliminar o minério de manganês, devido ao fato que estudos anteriores feitos na unidade técnica da Usiminas Cubatão não mostraram correlação com o aumento do rendimento do Manganês no aço.

\subsubsection{Escória beneficiada}

A ideia de utilizar a escória gerada no processo, seria para reduzir o custo com escorificantes (Cal e Dolomita) devido a composição rica em CaO. Este material foi implantado na Usiminas Cubatão em 2008 como escorificante durante o sopro e reparo com escória.

O seu preparo consiste em recuperar a escória gerada no processo, simplesmente uma classificação granulométrica e uma separação magnética. A composição final pode ser vista na Tabela 3.

* Contribuição técnica ao 45 Seminário de Aciaria - Internacional, 25 a 28 de maio de 2014, Porto Alegre, RS, Brasil. 


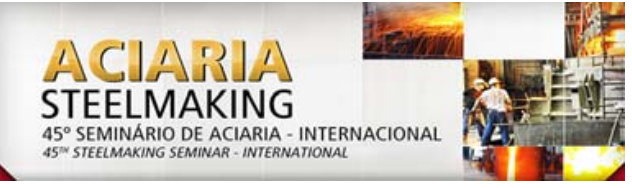

Tabela 3. Composição típica de uma escória beneficiada

\begin{tabular}{|l|l|l|l|l|l|l|l|l|}
\hline Elemento & $\mathrm{MgO}$ & $\mathrm{Al}_{2} \mathrm{O}_{3}$ & $\mathrm{SiO}_{2}$ & $\mathrm{P}_{2} \mathrm{O}_{5}$ & $\mathrm{SO}_{3}$ & $\mathrm{CaO}$ & $\mathrm{MnO}$ & $\mathrm{Fe}_{2} \mathrm{O}_{3}$ \\
\hline Teor & 6,88 & 3,73 & 13,04 & 1,12 & 0,09 & 35,03 & 11,10 & 20,00 \\
\hline
\end{tabular}

Percebe-se o baixo teor de $\mathrm{MgO}$ da escória (6,88\%), sendo que o valor mínimo da dolomita é de $36 \%$. Outro elemento em destaque é o $\mathrm{MnO}(11,1 \%)$, sendo que o mesmo é um fluidificante para a escória, o que permite um maior ataque do revestimento pela escória.

Em função desta análise optou-se em retirar a escória bitolada, sendo que o balanço de massa foi compensado com a Cal, Dolomita Crua e Calcinada.

\section{RESULTADOS E DISCUSSÃO}

\subsection{Nível de Oxidação do Banho}

O sopro combinado garante um menor nível de oxidação do banho, aumentando o rendimento metálico. Com menor teor de oxigênio livre, menor o ataque no refratário, e com isso uma maior vida do revestimento. Na figura 6, observam-se os resultados de dois convertedores em operação, sendo que o LD6 (ventaneiras fechadas com 1850 corridas) e o LD7 (com ventaneiras operando). Percebe-se que o sopro combinado, reduziu o nível de oxidação em comparação ao convertedor sem o sopro combinado.

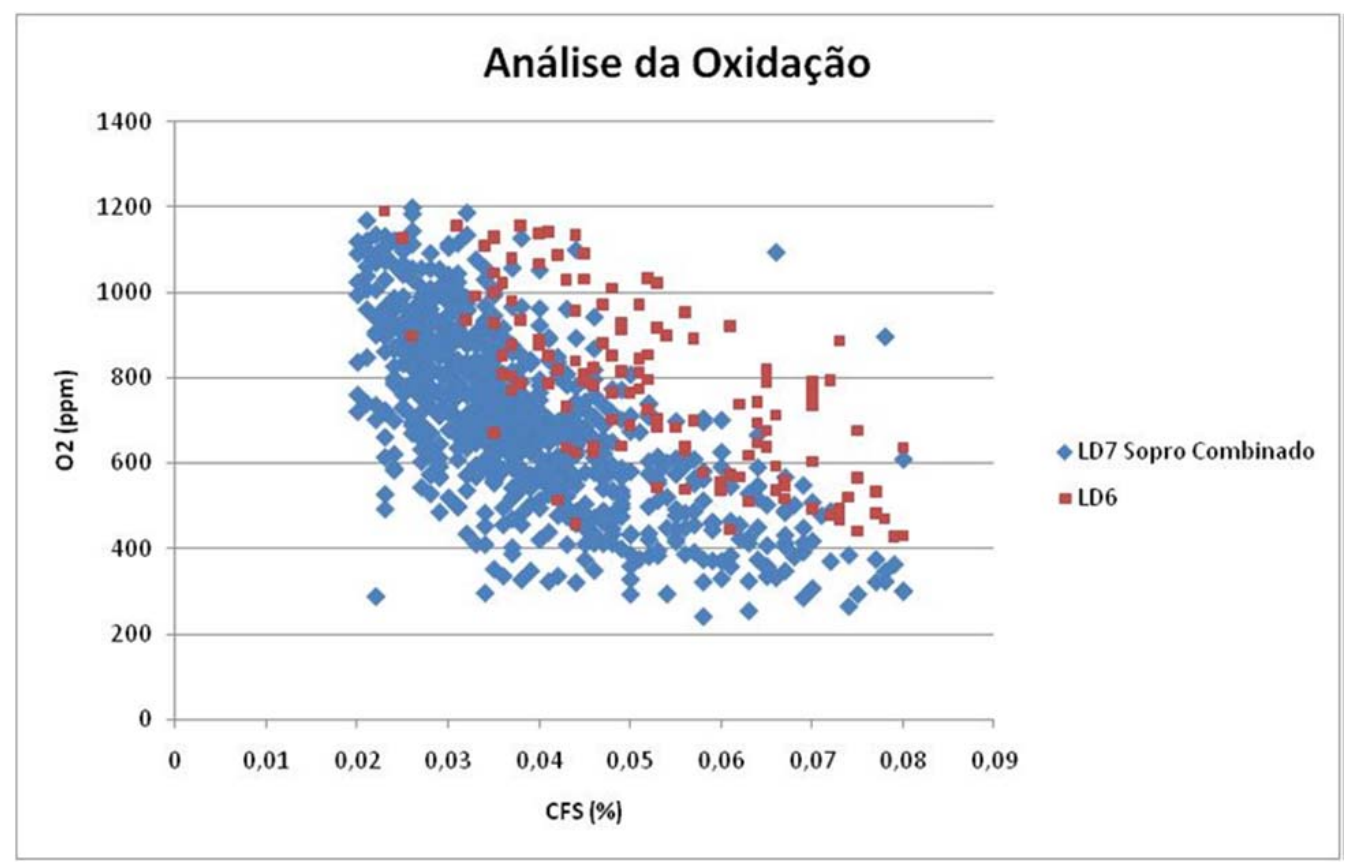

Figura 6. Análise da oxidação do aço com e sem o sopro combinado.

\subsection{Desempenho do revestimento refratário}

A partir das mudanças implantadas em 2012, foi possível reduzir o consumo de massa de reparo, no convertedor 7 atingindo 5941 corridas e com consumo de $0,81 \mathrm{~kg} / \mathrm{t}$. De acordo com o modelo de consumo de massa em função da vida, o valor teórico para este número de corridas seria $1,3 \mathrm{~kg} / \mathrm{t}$. Isto significa, que mesmo com o aumento da vida, obteve-se um consumo adequado sem risco a operação. A Figura 7 mostra a evolução das campanhas dos convertedores a partir de 2012. De

* Contribuição técnica ao 45 Seminário de Aciaria - Internacional, 25 a 28 de maio de 2014, Porto Alegre, RS, Brasil. 
acordo com o gráfico a barra corridas representa a vida do convertedor. E a barra ventaneiras, representa $o$ número de corridas com que foram fechadas as ventaneiras. A linha Gunning e Geral representam o consumo específico dos refratários.

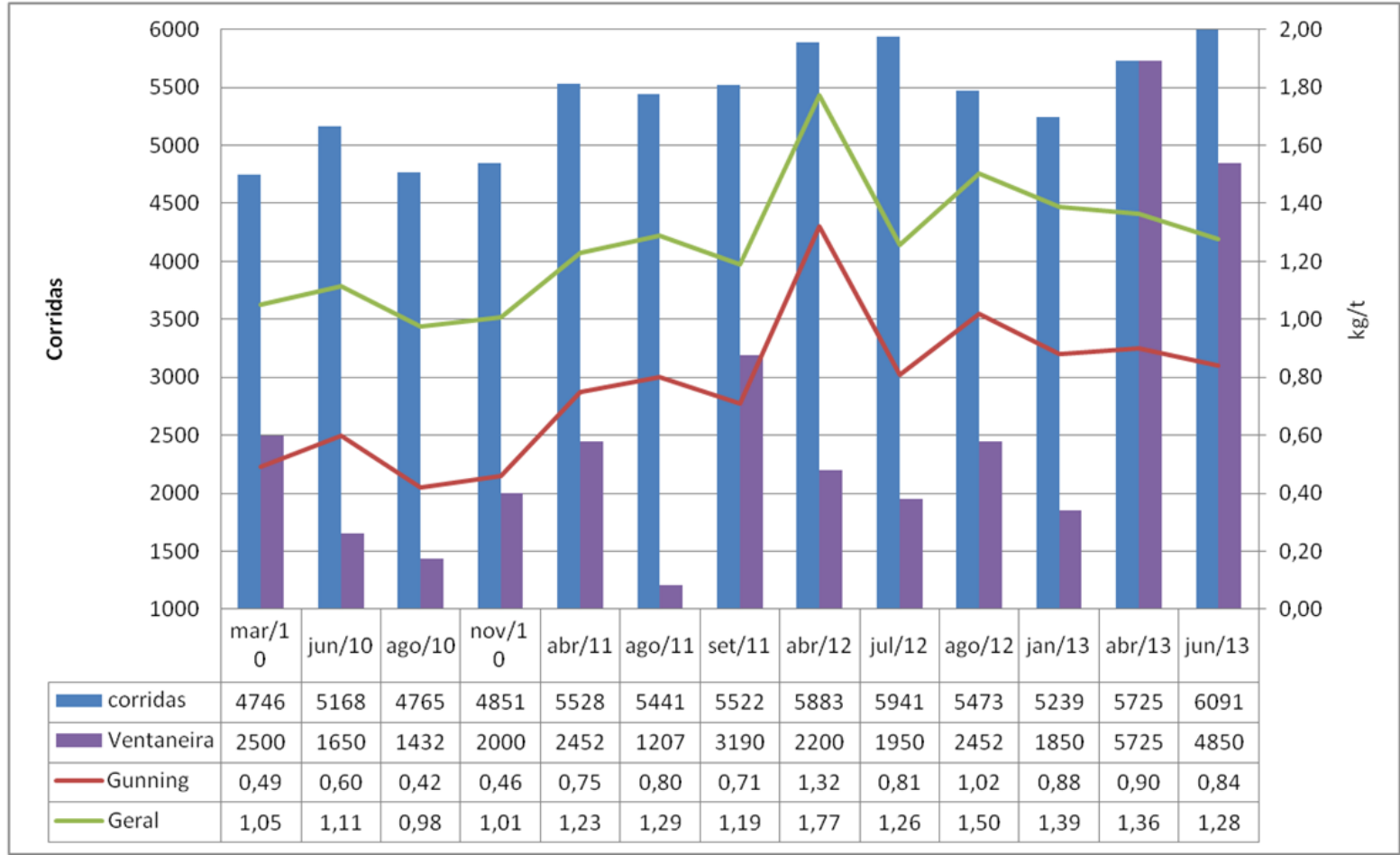

Figura 7. Evolução das campanhas dos convertedores da Usiminas Cubatão.

Neste mesmo período teve-se os melhores resultados do Sopro Combinado, as ventaneiras atingiram 4850 corridas no Convertedor 5 e 5.725 corridas no convertedor 7. A média histórica não passava dos 2500 corridas.

\subsection{Resultado do Novo Tijolo para os Munhões}

Após implantação no convetedor 7 do novo material para os munhões, fez-se uma avaliação comparativa com a campanha anterior no mesmo local. Houve a redução de $30 \%$ da taxa de desgaste, o que levou a postergar a massa de reparo antes com 1.500 corridas para 2.600 corridas. As Figuras 8 e 9 mostram o comparativo de desgaste entre campanhas do convertedor 7 .

* Contribuição técnica ao 450 Seminário de Aciaria - Internacional, 25 a 28 de maio de 2014, Porto Alegre, RS, Brasil. 

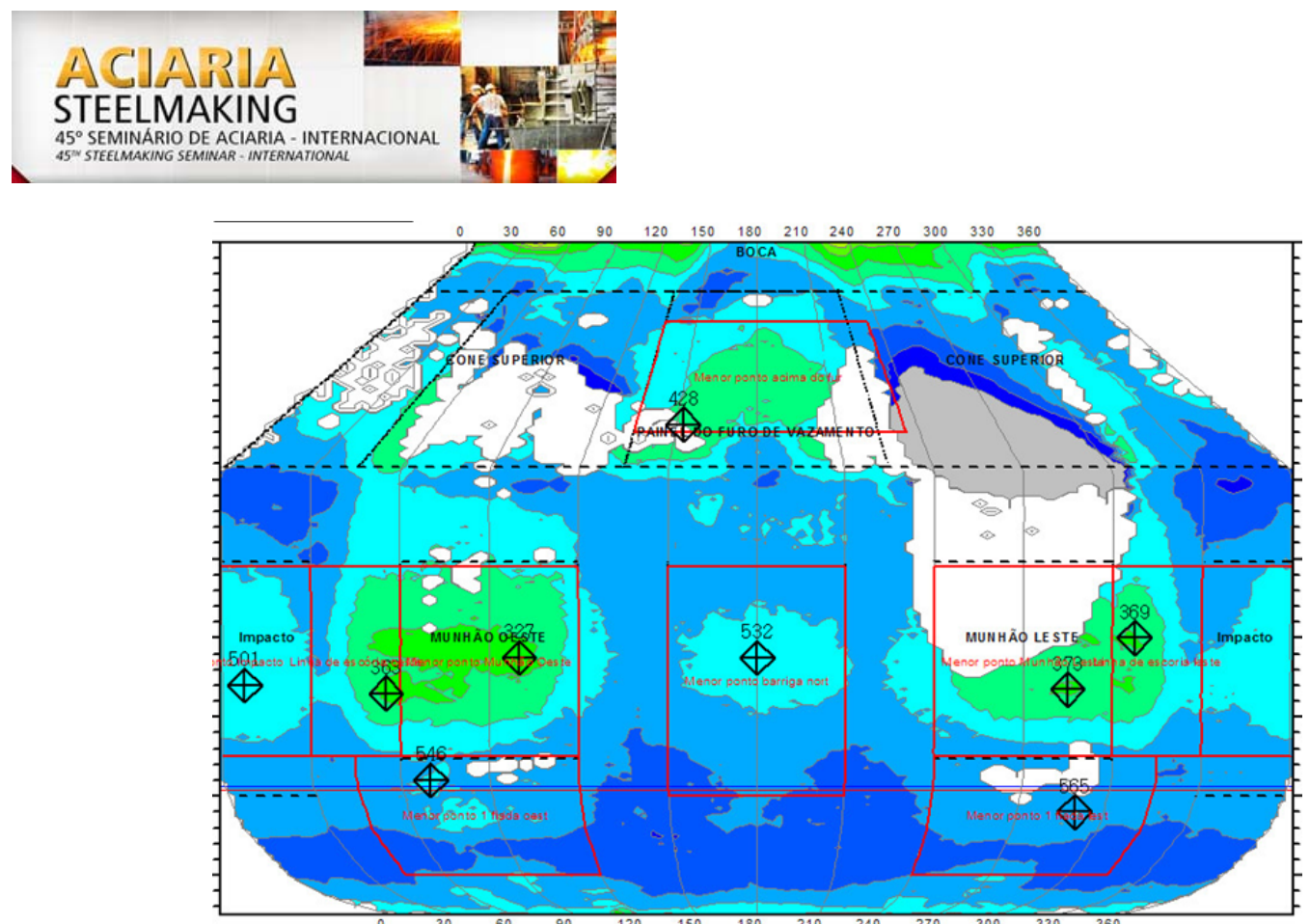

Figura 8. Medição a laser do convertedor (projeto antigo com 1.182 corridas).

De acordo com a medição do Convertedor com 1.182 corridas, o residual do munhão apresentou o valor residual de $327 \mathrm{~mm}$. A espessura original do munhão é $750 \mathrm{~mm}$. O que corresponde a uma taxa de desgaste de 0,36 mm/corrida. Neste ritmo o inicio das projeções seria atingindo com 1.700 corridas.

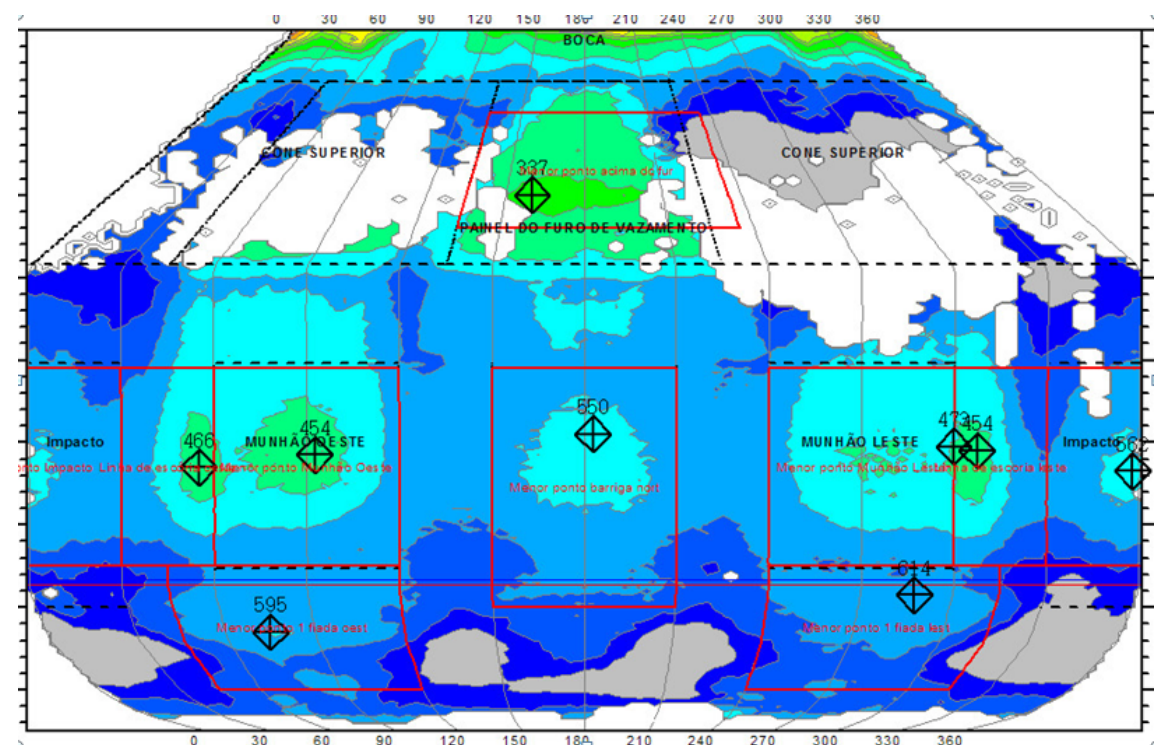

Figura 9. Medição a laser do convertedor (projeto novo com 1.206 corridas).

De acordo com a medição do Convertedor com 1.206 corridas, o residual do munhão apresentou o valor mínimo de $454 \mathrm{~mm}$. O que corresponde a uma taxa de desgaste de $0,25 \mathrm{~mm} /$ corrida. Neste ritmo o inicio das projeções seria atingindo com 2.400 corridas.

\subsection{Recuperação da Sola pela Dolomita Crua}

A implantação da dolomita crua no reparo com escória foi bem eficiente, a Figura 10 mostra a medição a laser antes do reparo e após o reparo com dolomita crua. Houve recuperação da sola em $120 \mathrm{~mm}$ nesta corrida em questão.

\footnotetext{
* Contribuição técnica ao 450 Seminário de Aciaria - Internacional, 25 a 28 de maio de 2014, Porto Alegre, RS, Brasil.
} 

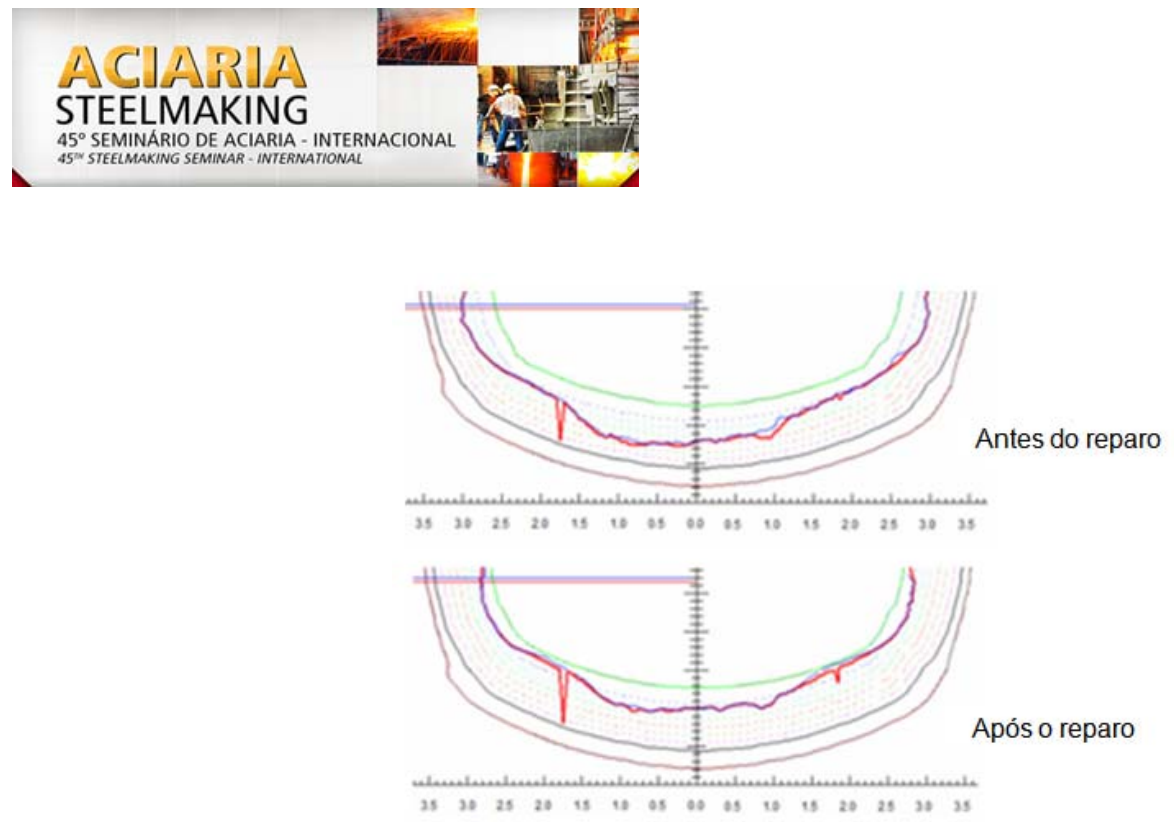

Figura 10. Recuperação da sola pela dolomita crua.

Esta pratica garantiu uma recuperação da sola do revestimento, proporcionando a eliminação do reparo com massa resinada. O tempo de cura dessa massa é em torno de 2 horas, o que prejudica no índice de utilização dos convertedores.

\section{CONCLUSÃO}

De acordo com os resultados obtidos, foi possível aumentar o desempenho do revestimento do convertedor. Com a melhora da condição dos escorificantes, foi possível eliminar o uso do reparo com massa resinada e redução do consumo de massa de projeção. O aumento da vida útil das ventaneiras foi outro destaque do trabalho, o que mostra que a pesquisa científica tem grande eficácia, levando a resultados nunca antes alcançados no grupo Usiminas. Em resumo dos resultados podemos listar:

1. Aumento da vida útil do convertedor, com consumo de massa reduzido;

2. Eliminação do uso de massa resinada;

3. Aumento de $100 \%$ da vida útil das ventaneiras no convertedor 7 atingindo 5.725 corridas e $80 \%$ do convertedor 5 atingindo 4.850 corridas;

Redução do custo de escorificantes com o uso da dolomita crua.

\section{REFERÊNCIAS}

1 Martins AA, Malynowskyj A, Silva CA, Barão CD, Castro LFA; Faria MAA, et al. Fabricação de Aço em Forno Básico a Oxigênio [apostila de curso]. Vitória: ABM; 2005.

2 Lee MS, Evans TJ. Control of Refractory Back Attack and Tuyere Metal Penetration During Bottom Gas Injection in the BOF. Iron \& Steelmaker. 2003.

3 Lima HAA. Modelamento Físico do Sopro Combinado em Convertedores BOF [Dissertação de mestrado]. Belo Horizonte: Escola de Engenharia da UFMG; 2011.

4 Cruz CRV, Jordão MAP, Carvalho CM, Jon M, Esmeraldo RM, Goncalves GE, et al. Refratários Para Equipamentos Siderúrgicos [apostila de curso]. São Paulo: ABM; 1982.

5 Jon M. Melhorias no Comportamento dos Revestimentos dos Conversores LD por Adição de Magnésia. Metalurgia - ABM. 1982; 38( 300):665-671.

6 Magnesita Refratários S.A. Ficha de Dados Técnicos. Contagem: Magnesita; 2013.

* Contribuição técnica ao 450 Seminário de Aciaria - Internacional, 25 a 28 de maio de 2014, Porto Alegre, RS, Brasil. 